Article

\title{
Lessons Learned from the Construction, Inspection, and Defect Assessment of Reinforced Concrete Foundations for Wind Turbines
}

\author{
Alexandre Mathern *(i) and Jonas Magnusson
}

Citation: Mathern, A.; Magnusson, J. Lessons Learned from the Construction, Inspection, and Defect Assessment of Reinforced Concrete

Foundations for Wind Turbines. Appl. Sci. 2022, 12, 1443. https://doi.org/ 10.3390/app12031443

Academic Editors: Gabriele Bertagnoli and Diego Gino

Received: 21 December 2021

Accepted: 22 January 2022

Published: 28 January 2022

Publisher's Note: MDPI stays neutral with regard to jurisdictional claims in published maps and institutional affiliations.

Copyright: (C) 2022 by the authors. Licensee MDPI, Basel, Switzerland. This article is an open access article distributed under the terms and conditions of the Creative Commons Attribution (CC BY) license (https:// creativecommons.org/licenses/by/ $4.0 /$ )
NCC Infrastructure, NCC Sverige AB, Lilla Bommen 3C, 40514 Gothenburg, Sweden; jonas.magnusson@ncc.se

* Correspondence: alexandre.mathern@ncc.se

\begin{abstract}
Foundations of wind turbines are subject to challenging conditions during their service life as they support ever larger wind turbines under complex loading situations. There have been numerous reports of cracked concrete foundations of wind turbines. Cracking can impair the durability and serviceability of the foundations, thereby leading to very expensive repairs or even to premature failure of the structure. To avoid cracking-related problems and improve the quality of concrete foundations, it is important to gather information and experience from the production stage and its outcome. However, although problems and defects in the construction of wind turbine foundations are widespread, they have very seldom been documented and reported, in particular from a contractor's perspective. This article analyses and critically reviews data collected during the production, inspection, diagnosis, and repair activities conducted in relation to the construction of foundations for a wind farm project in Sweden. The extent of defects observed on individual foundations is assessed and used to investigate the eventual relation between the observed deviations and different production aspects. Investigation methods to determine the importance of these defects and their consequences and possible remediation measures are also discussed. Finally, recommendations are proposed to improve the quality control of wind turbine foundations.
\end{abstract}

Keywords: wind energy; onshore; foundation; reinforced concrete; construction; non-conformities; cracking

\section{Introduction}

Today, wind energy is developing at a record pace as the demand for renewable energy increases. In 2020, a wind power capacity of 93 GW was installed globally (including $87 \mathrm{GW}$ onshore), which corresponds to the installation of tens of thousands of new wind turbines, and annual installations are expected to keep increasing substantially during the coming decade [1]. Onshore wind turbines' foundations are supported by massive concrete structures, which are commonly built in remote locations with tough weather conditions. Their construction represents a challenging task, which requires the coordination of a wide range of different and complex aspects (e.g., material, environment, equipment, human). It is important to conduct proper planning prior to the construction that encompasses these aspects.

As reported in several other studies [2,3], a large proportion of existing wind turbine foundations are cracked or have other types of defects. For instance, there have been numerous records of deficiencies in wind turbine foundations and towers, in particular of cracking in the concrete [4,5]. The inspection of several thousands of wind turbine foundations in Germany a few years ago concluded that more than a quarter of wind turbine foundations examined need remedial measures due to inappropriate structural detailing or poor construction [6]. In China, corrosion and cracks are the main defects identified on towers and foundations, and it has been observed there that damages and failures are most often caused by fatigue under normal operating conditions [7]. Crack 
propagation within a concrete foundation due to design deficiencies was identified as the cause of the collapse of a 3-MW wind turbine in Canada, leading to the costly replacement of the foundations for 50 turbines at the same wind farm [8,9]. Frequent problems have also been reported concerning embedded anchor rings [2,3,5], which are commonly used to connect the tower to the concrete foundation. This is an extensively used solution worldwide. Excessive movements of up to tens of millimetres in the vertical direction have been observed. According to Currie et al. [3], the problem is widespread but often not reported because of commercial reasons. Similarly, defects are seldom reported and assessed in detail in the literature and the causes of these defects and their relation to the construction process and design aspects have rarely been investigated. Additionally, it is worth noting that cracks in the concrete and other defects in wind turbine foundations may often not be detected as the foundations are often almost entirely covered and cannot be inspected visually after the wind turbine is installed.

Defects or anomalies affecting the wind turbine foundations may affect the durability of the foundation and the serviceability of the turbines or even affect their stability. To preventively address these issues, which have important economic and safety consequences, it is important to gather information from wind farm construction projects and study possible deficiencies to prevent the resurgence of these anomalies. According to Hassanzadeh [2], a defective design process is the main cause of damage to wind turbine foundations, as construction solutions developed for smaller wind turbines are used and applied to larger structures. In fact, the size of wind turbines has increased exponentially in recent years, and the hub height of a wind turbine installed today can reach more than $140 \mathrm{~m}$ [10]. Hassanzadeh [2] also pointed out that investigations carried out should have been carried out to improve the design of new foundations. Despite the occurrence of damages and failures, structural health monitoring of onshore wind turbine foundations has attracted minimal interest so far and has been limited to a few single installations for research purposes [11-13].

Cracking in concrete structures is ineluctable and nearly all concrete structures exhibit a certain kind of cracking. Cracks in concrete structures are often classified in two main categories depending on whether they occur before or after hardening of the concrete [14,15]. Under each of these categories, various types of cracks are associated with different underlying causes, as described in Figure 1. Cracks may be structural (i.e., load-induced) or non-structural. Generally, structural cracks are included in the design as they mobilise the tensile properties of the reinforcing steel, which is adequately placed in the structure to make up for the low tensile strength of the concrete. Non-structural cracks encompass many different types and causes that are related to the nature of the concrete material, its constituents, and its interaction with the environment. A thorough examination is often required to categorize different types of cracks. For instance, plastic settlement cracks and plastic shrinkage cracks, both appearing in the first hours after casting before the concrete hardens, are particularly hard to distinguish. The former are characterized by a crack pattern that follows the pattern of the surface reinforcement, which constitutes the main aspect distinguishing them from the latter [16]. Cracks that form in the early stages may increase in width and size over time, sometimes over several years, due to a combination of different causes.

It is crucial to control the cracking of concrete structures since uncontrolled cracking leads, in many cases, to poor function and durability of the structures. The most common concern is that cracks will render the concrete more permeable and facilitate the ingress of moisture, gas, chloride ions, and other chemicals within the concrete, which will in turn increase the risk of corrosion of the reinforcement bars during the service life of the structure. The high $\mathrm{pH}$ of the concrete pore solution normally protects the reinforcing steel by forming a naturally passivated surface around it. However, the ingress of chlorides in the concrete may break this passive layer and lead to the initiation of corrosion in the presence of oxygen and water. The passive layer may also be destroyed due to carbonation, when carbon dioxide and moisture penetrate the concrete and lead to a series of reactions with the 
hydrated cement and the pore solution, which results in a $\mathrm{pH}$ drop of the concrete $[17,18]$. Corrosion induced by chlorides is mostly a concern for wind turbines that are located offshore or in coastal regions onshore [19].

Corrosion of the reinforcement bars leads to further degradation of the structure due to the expansive nature of the corrosion products, causing concrete spalling and loss of bond [15]. Reinforcement corrosion is one of the main mechanisms of deterioration of concrete structures, and it is considered by the concrete community to be directly related to the environmental exposure condition of the structure, to the number of cracks, and the concrete quality and cover thickness to the reinforcement $[15,20]$. Cracks can also impair the water or gas tightness and negatively affect the aesthetics of a structure, but these requirements are normally not applicable to wind turbine foundations, which are commonly almost entirely buried and are not subject to specific tightness requirements. Today, cracks are controlled by reinforcement using either traditional steel bars or fibres. The purpose of crack control is to keep the crack widths below a defined limit. An extensive description of crack control in concrete and the theory of cracking is given in [21,22]. The width of the cracks-independently of the causes-are commonly limited to between 0.3 and $0.4 \mathrm{~mm}$ for reinforced members and $0.2 \mathrm{~mm}$ for prestressed members [23].

Cracks formation

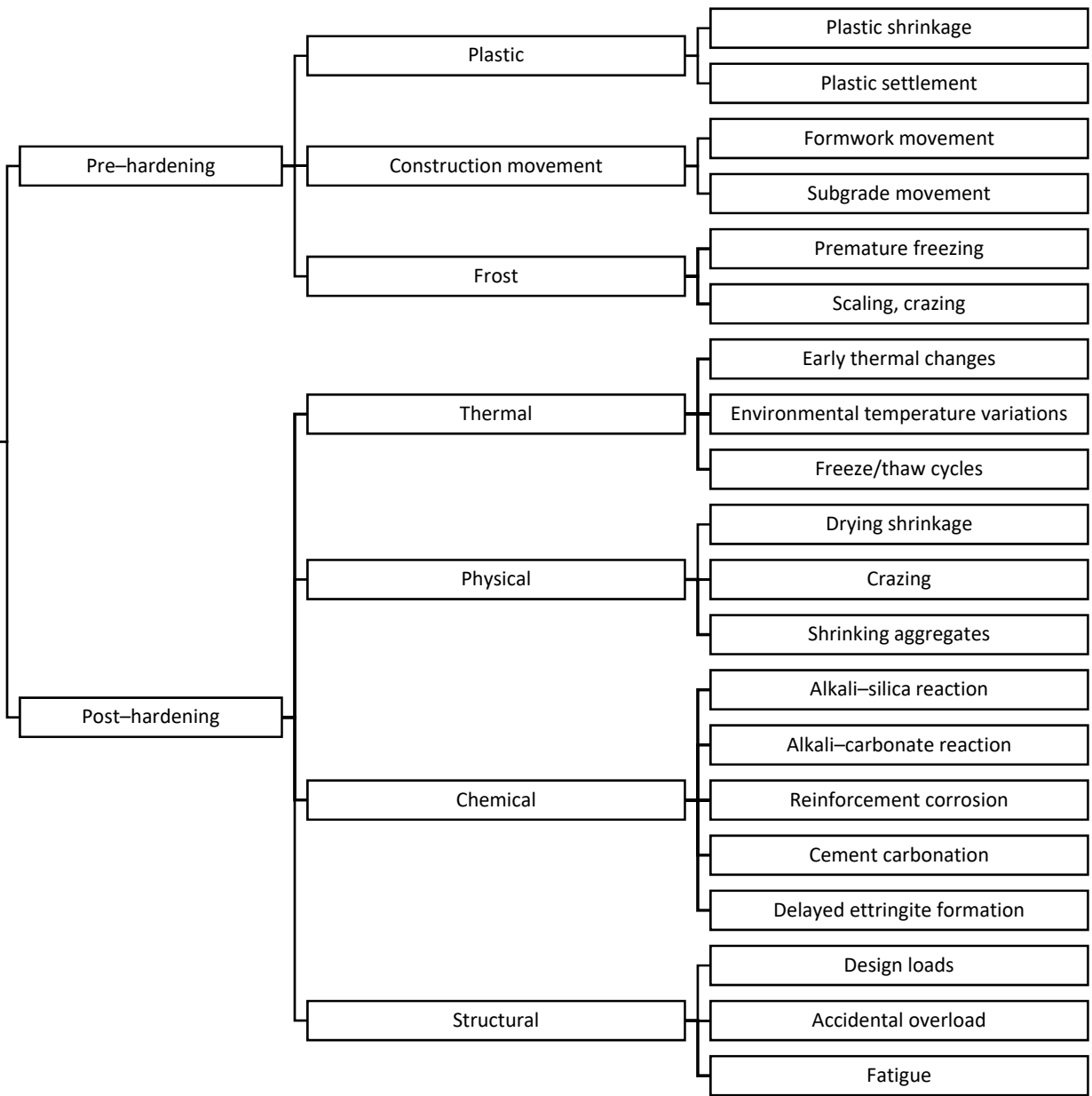

Figure 1. Factors leading to the formation of different types of cracks in concrete. Elaborated from $[14,15,24]$.

The aim of this study was to assess defects that emerged in the construction of foundations for wind turbines and analyse their relation to production aspects and design requirements. For this purpose, available field data from the construction and inspection of foundations at an onshore wind farm in Sweden were compiled and critically analysed. The term defect is here used to refer to cracks, deviations, nonconformities, or singularities 
observed on the foundations, whether or not they have an impact on the durability and functionality of the foundations.

\section{Method}

The construction of foundations at an onshore windfarm in the north of Sweden was used as case study in this work. The wind farm covers a large area of land with a range of different geotechnical conditions that required different types of foundations. This study focuses on the about two dozen reinforced concrete gravity-based foundations that represent part of the foundations built in the project. The foundations were designed for a design service life of 25 years. The design was conducted in accordance with the European Eurocode design standards taking into account the environmental exposure class $\mathrm{XC} 4 / \mathrm{XF}$. The allowable crack width was chosen as $0.4 \mathrm{~mm}$, which corresponds to the standard requirement for a design service life of 50 years. A freeze-thaw resistant concrete, of strength class C35/45, based on CEM I 42.5 N SR3 MH/LA Portland cement was used, with a water-to-cement ratio of 0.55 . The construction of the foundations was spread over a period of one year in the first half of the 2010s.

The gravity-based foundations were designed as circular foundations with radial and circular top reinforcement and a square net of bottom reinforcement (see Figure 2a,b). The shear reinforcement used consists of so-called T-headed bars, which have a hook at one end (top) and a welded plate at the other end (bottom), as shown in Figure 2c. The foundations have a diameter and height of approximately $21 \mathrm{~m}$ and $2.3 \mathrm{~m}$, respectively, which required a volume of concrete of about $550 \mathrm{~m}^{3}$ (see Figure 2c). They were cast on blinding concrete over a compacted filling of more than $500 \mathrm{~mm}$ of crushed rock. The top of the foundations is sloping and was cast without a top form. The different stages of the construction of the foundations are illustrated in Figure 3.

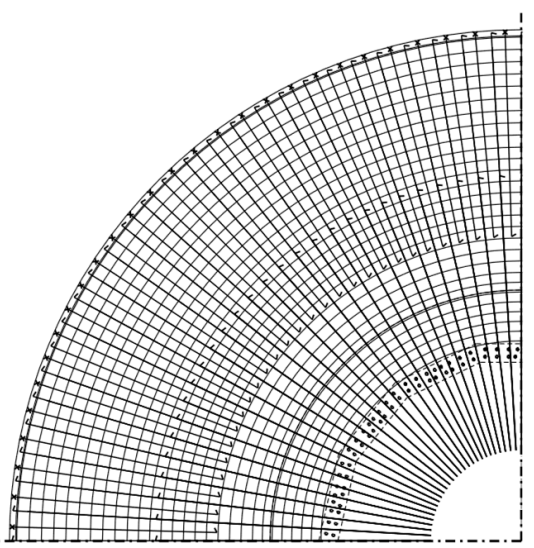

(a)

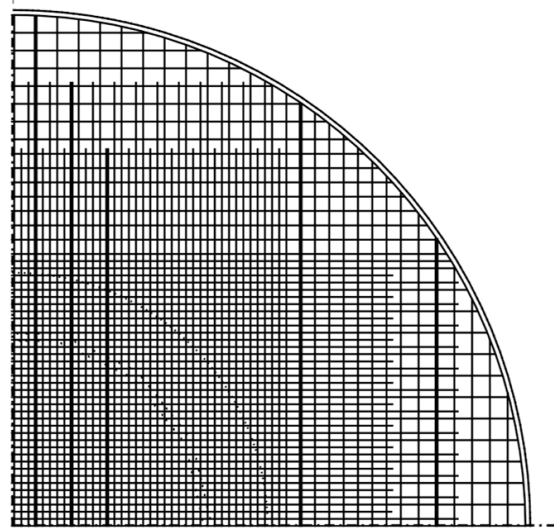

(b)

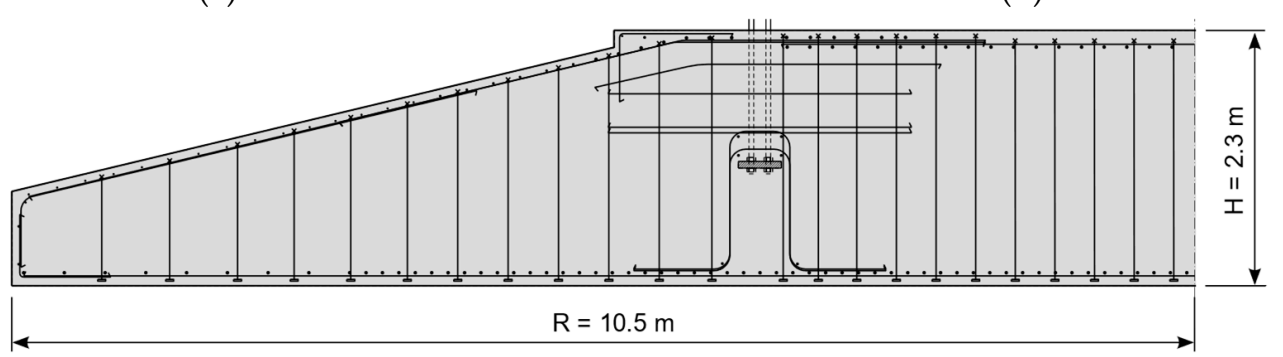

(c)

Figure 2. The studied reinforced concrete gravity-based foundation studied: (a,b) plan views of a quadrant of the foundation showing (a) the top reinforcement layout and (b) the bottom reinforcement layout; and (c) the radial section of the foundation. 


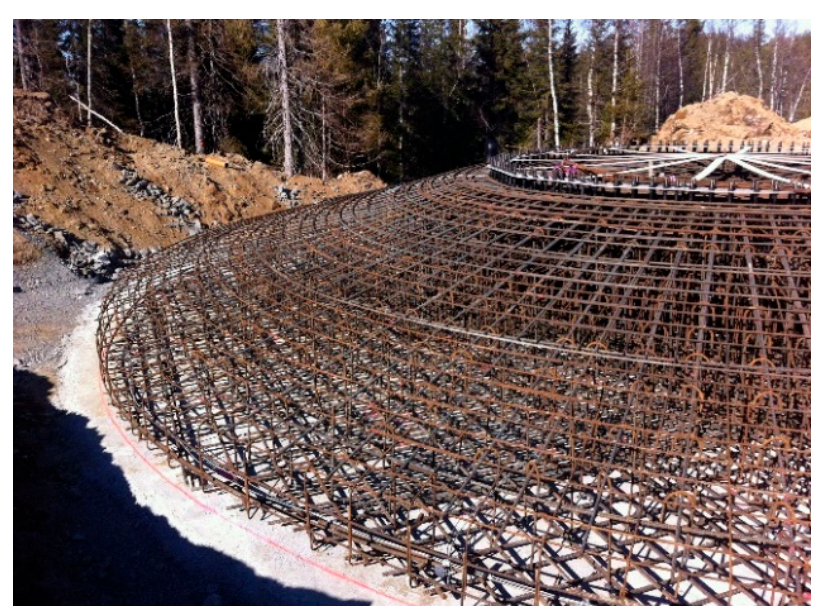

(a)

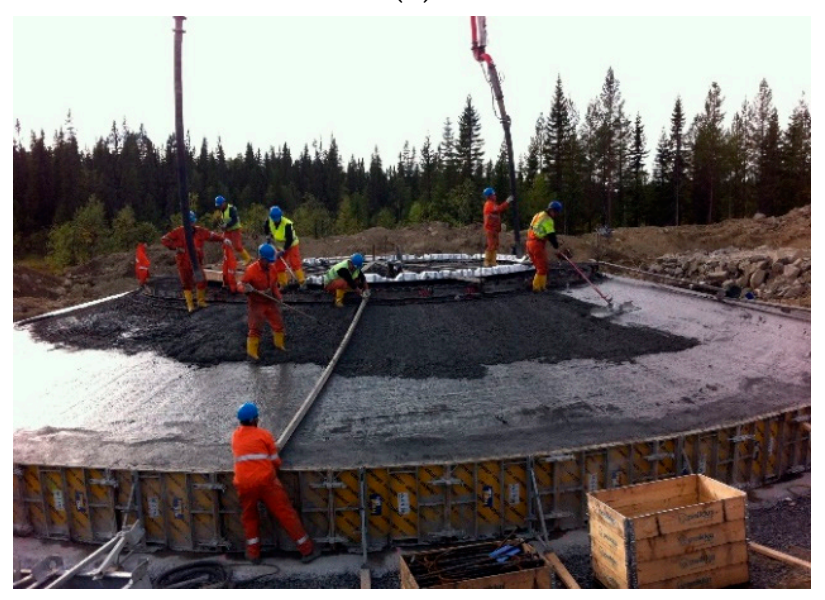

(c)

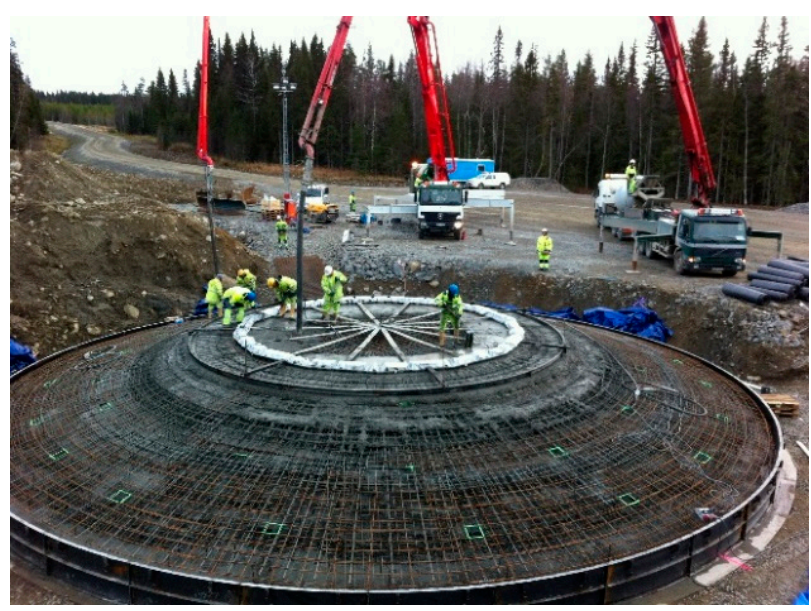

(b)

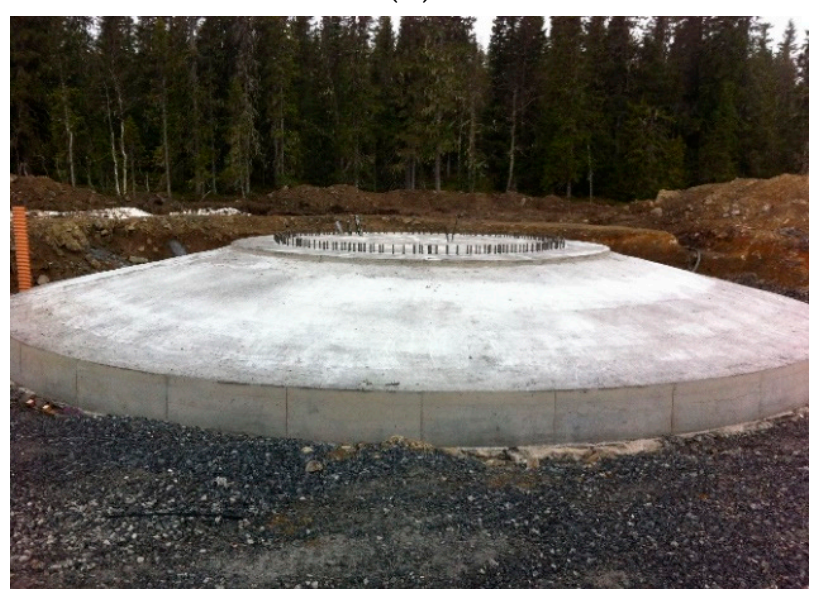

(d)

Figure 3. Photos of the construction of the foundations, (a) after placing the reinforcement, (b,c) during casting of the concrete, and (d) the completed foundation before backfilling with soil.

Following the construction of the foundations, visual inspection was carried out. The first observations of cracks were made at the inspection round at the end of the construction. The cracks observed were located on the surface of the foundations and observed on foundations that were not backfilled. Based on these observations, further inspections were carried out by the general contractor and consulting engineers during the following years. Excavations were conducted to uncover all foundations for inspection and repair purposes. The actions that were undertaken included visual inspection of the foundations, the measurement and mapping of surface cracks, the measurement of the concrete cover, the extraction of samples from the foundations, and the repair of the identified defects.

Crack widths were visually measured using crack comparator cards (i.e., graduated transparent plastic cards with lines of various widths), as shown in Figure 4a. The concrete cover was assessed by a sonic surface measurement tool to map the distance between the surface and the top layer of steel reinforcement (see Figure $4 \mathrm{~b}$ ). The concrete cover was measured on average at 170 points spread over the foundation surface (up to 560 points on critical foundations). The measured crack widths together with the position and layout of the cracks, and the concrete cover measurements were reported on drawings of the foundations. Cores were drilled out from a number of foundations, as illustrated in Figure $4 \mathrm{c}$, in order to measure the concrete's in-situ compressive strength and density at different depths. The carbonation, the homogeneity of the concrete and the distribution of the aggregates were also assessed, and the bond between the concrete and the reinforcement bars was visually checked. These cores were collected from foundations that exhibited 
surface cracking, when the foundations were between less than a year old and up to approximately three years old. On a few foundations, the top concrete layer was removed locally using high-pressure water jetting for additional inspection and to remediate localised defects (see Figure 4d).

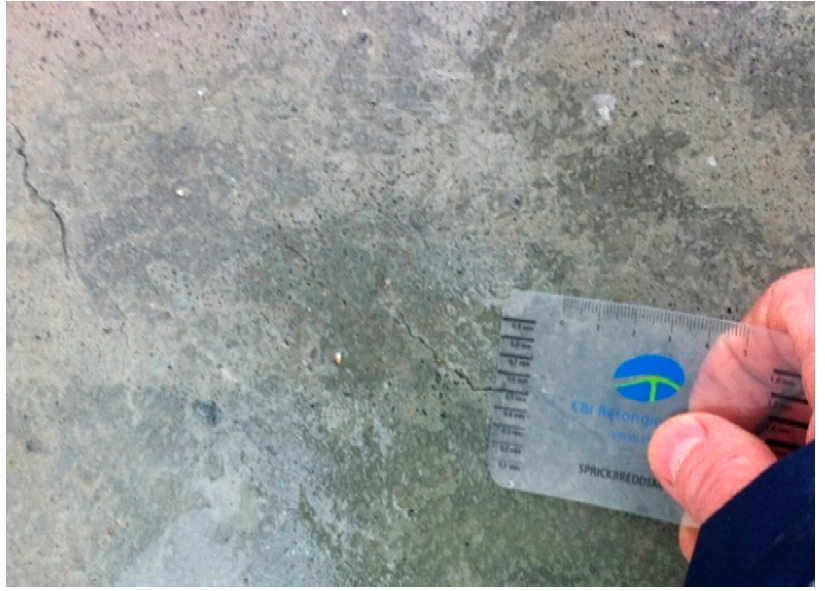

(a)

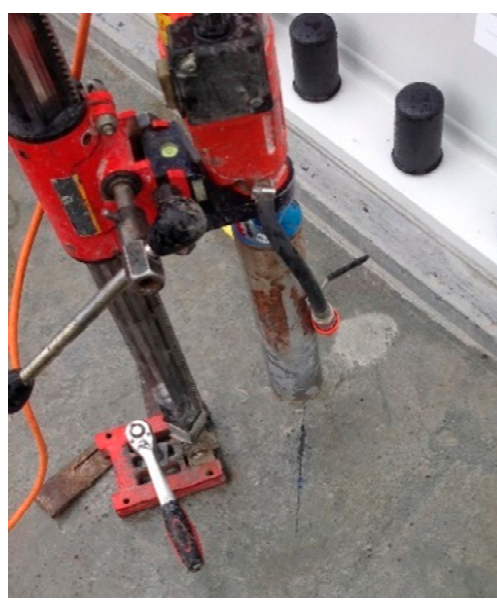

(c)

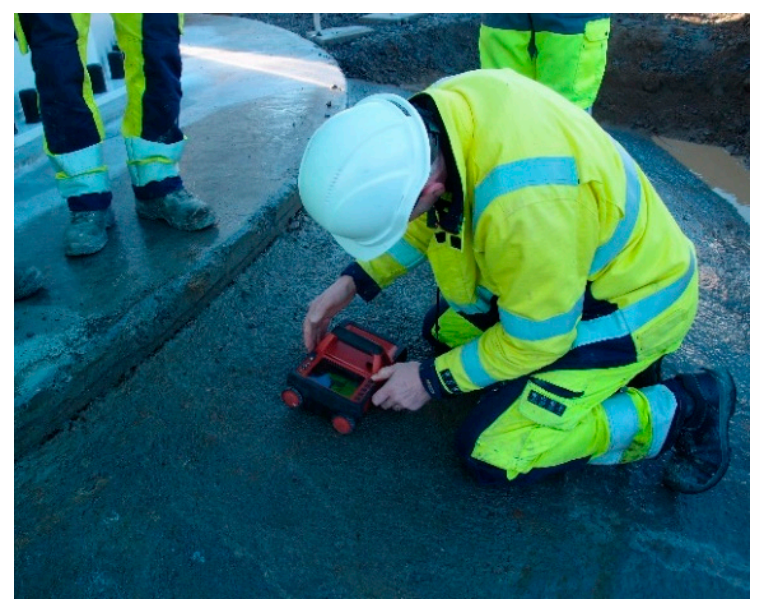

(b)

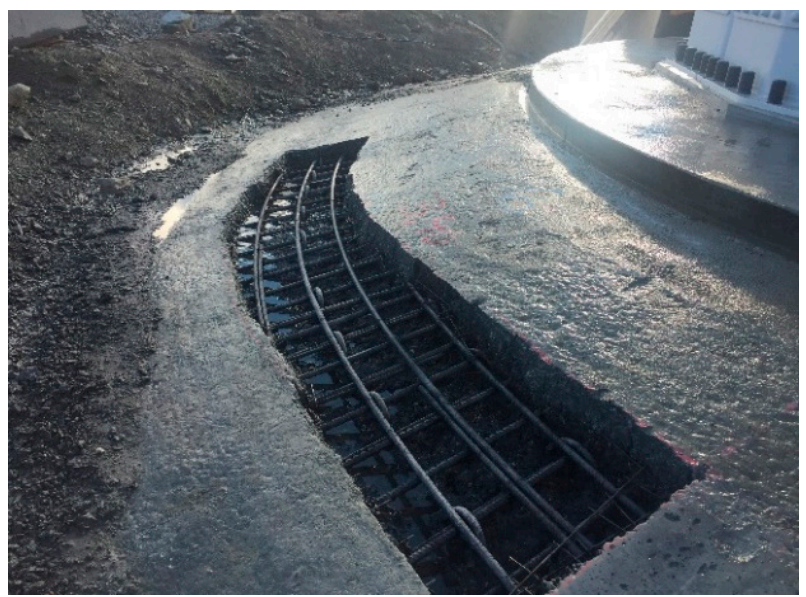

(d)

Figure 4. (a) Measurements of the crack width using a crack comparator card, (b) measurement of the concrete cover using a concrete scanner, (c) drilling of concrete cores from the foundations, and (d) after water jet removal of the top concrete layer.

For the purpose of this study, data were gathered from technical documents and drawings from the design stage; daily logs from the construction stage; and photos, inspection, and measurement reports from the inspection stage. When needed, complementary information was obtained through personal communication with persons involved in these different stages.

A method used to evaluate the extent of the defects on single foundations was defined in this work based on the information available and its level of accuracy. The different types of defects that were evaluated are detailed in Table 1, which forms the basis of the assessment method.

The different types of defects assessed were then aggregated by defining defect indexes as listed in Table 2. 
Table 1. Defects assessed on the gravity-based foundations.

\begin{tabular}{|c|c|c|c|}
\hline Type of Defect & Symbol & Assessment Scale & Value \\
\hline $\begin{array}{l}\text { Number of cracks on the external } \\
\text { inclined surfaces of the foundation }\end{array}$ & $D_{1,1 a}$ & $0-3$ & $\begin{array}{c}0: \text { no crack } \\
\text { 1: few cracks }(<10) \\
\text { 2: several cracks }(10-20) \\
\text { 3: many cracks }(>20)\end{array}$ \\
\hline $\begin{array}{l}\text { Size of cracks on the external } \\
\text { inclined surfaces of the foundation }\end{array}$ & $D_{1,1 b}$ & $0-3$ & $\begin{array}{l}\text { Based on crack width measurements, } \\
\text { with } w_{c r} \text { corresponding to the maximum } \\
\text { crack width measured: } \\
0: \text { no crack } \\
\text { 1: } w_{c r}<0.4 \mathrm{~mm} \\
\text { 2: } 0.4 \mathrm{~mm} \leq w_{c r}<0.5 \mathrm{~mm} \\
\text { 3: } 0.5 \mathrm{~mm} \leq w_{c r}\end{array}$ \\
\hline $\begin{array}{l}\text { Extent of cracking on the } \\
\text { central horizontal surfaces }\end{array}$ & $D_{1,2}$ & $0-3$ & $\begin{array}{l}\text { 0: no crack } \\
\text { 1: minor cracking } \\
\text { 2: moderate cracking } \\
\text { 3: severe cracking }\end{array}$ \\
\hline $\begin{array}{l}\text { Radial temperature cracks at the periphery } \\
\text { of the foundation and } \\
\text { extending on the inclined surface }\end{array}$ & $D_{1,3}$ & $0-1$ & $\begin{array}{l}\text { 0: no observation of cracks } \\
\text { 1: observation of cracks }\end{array}$ \\
\hline Insufficient concrete cover & $D_{2,1}$ & $0-3$ & $\begin{array}{l}\text { 0: sufficient concrete cover } \\
\text { 1-3: insufficient concrete cover: } \\
\text { 1: at less than } 6 \text { locations } \\
\text { 2: at } 6-10 \text { locations } \\
\text { 3: at more than } 10 \text { locations }\end{array}$ \\
\hline Incorrectly installed reinforcement & $D_{2,2}$ & $0-1$ & $\begin{array}{l}0: \text { no observation of wrong placement } \\
1 \text { : observation of wrong placement }\end{array}$ \\
\hline General finish aspect of the concrete surface & $D_{2,3}$ & $0-1$ & $\begin{array}{l}\text { Based on visual inspection: } \\
\text { 0: good surface finish } \\
\text { 1: irregular surface finish }\end{array}$ \\
\hline $\begin{array}{l}\text { Casting too high relative to } \\
\text { the tower anchor bolts }\end{array}$ & $D_{2,4}$ & $0-1$ & $\begin{array}{l}\text { 0: no observation of problem } \\
\text { 1: observation of problem }\end{array}$ \\
\hline $\begin{array}{c}\text { Other localized casting defects } \\
\text { under the soil level }\end{array}$ & $D_{2,5}$ & $0-1$ & $\begin{array}{l}\text { 0: no observation of problem } \\
\text { 1: observation of problem }\end{array}$ \\
\hline
\end{tabular}

Table 2. Defect indexes used to assess the quality of the foundations.

\begin{tabular}{ccc}
\hline Defect Index & Index & Scale \\
\hline General defect index & $I$ & $0-14$ \\
Crack index & $I_{1}$ & $0-7$ \\
Reinforcement and casting defect index & $I_{2}$ & $0-7$ \\
\hline
\end{tabular}

The general defect index was defined as the sum of the crack index and the reinforcement and casting defect index:

$$
I=I_{1}+I_{2}
$$

where the crack index is calculated from the underlying assessed defects $D_{1,1-3}$, as:

$$
I_{1}=\frac{D_{1,1 a}+D_{1,1 b}}{2}+D_{1,2}+D_{1,3}
$$

and the reinforcement and casting defect index is calculated as the sum of the defects $D_{2,1-5}$ :

$$
I_{2}=\sum_{i=1}^{5} D_{2, i}
$$




\section{Results}

\subsection{Defects Observed on the Constructed Foundations}

The defects observed on the uncovered foundations ranged from different types of surface cracks with different widths, insufficient concrete cover to the reinforcement, wrongly placed reinforcement, rust marks on the concrete surface, and voids in the concrete volume. Some of the defects were only observed on a few foundations (less than five foundations), such as incorrectly placed reinforcement $D_{2,2}$, and casting defects $D_{2,4}$ and $D_{2,5}$. Other defects were more widespread, such as insufficient concrete cover $D_{2,1}$, and irregular concrete surface $D_{2,3}$ (observed on 8 and 14 foundations, respectively). Finally, some defects were observed on most of the foundations, as was the case for all types of cracks $D_{1,1-3}$. All the observed cracks (categorized as plastic shrinkage cracks, plastic settlement cracks, and temperature cracks) were regarded as being production related (i.e., not structural). An overview of the defects observed is illustrated in Figure 5. The main difference between the plastic shrinkage cracks and the plastic settlement cracks lies in the fact that the latter appeared to run parallel to the underlying reinforcement bars, which was confirmed both by surface scanning and by the cores drilled on the foundations (including cores extracted at crack locations). Details of the defects are provided in Figures 6-9. Cracks that occurred on the horizontal pedestal surface of a foundation are illustrated in Figure 6 and the occurrence of rust marks is shown in Figure 7. Results from the concrete cover measurements carried out on the inclined surface of a foundation and of the crack inventory on the horizontal pedestal surface are summarized in Figure 8. Figure 9 shows the cores drilled on the inclined surface of a foundation at the plastic settlement cracks and on the pedestal of another foundation at the reinforcement location, respectively.

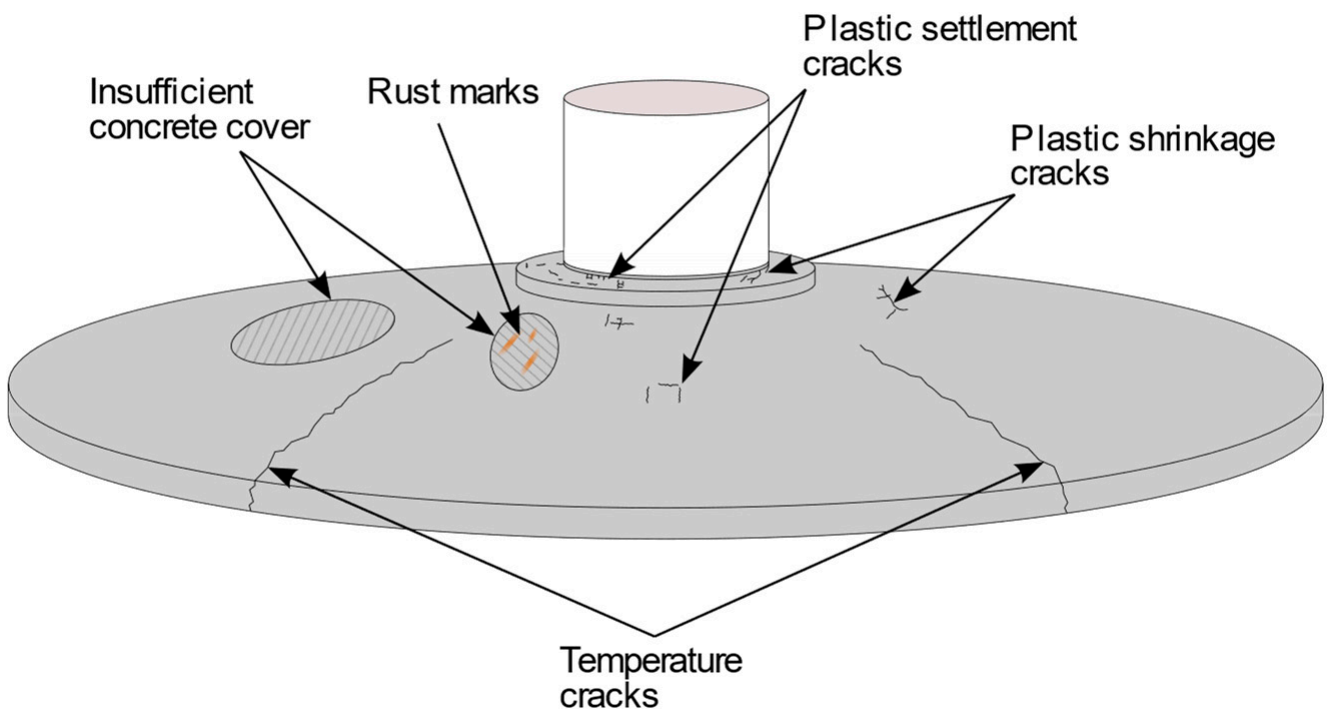

Figure 5. Sketch summarizing the different types of defects observed and some typical positions of the defects on the foundations (these defects were not all observed on a single foundation but on various foundations). 


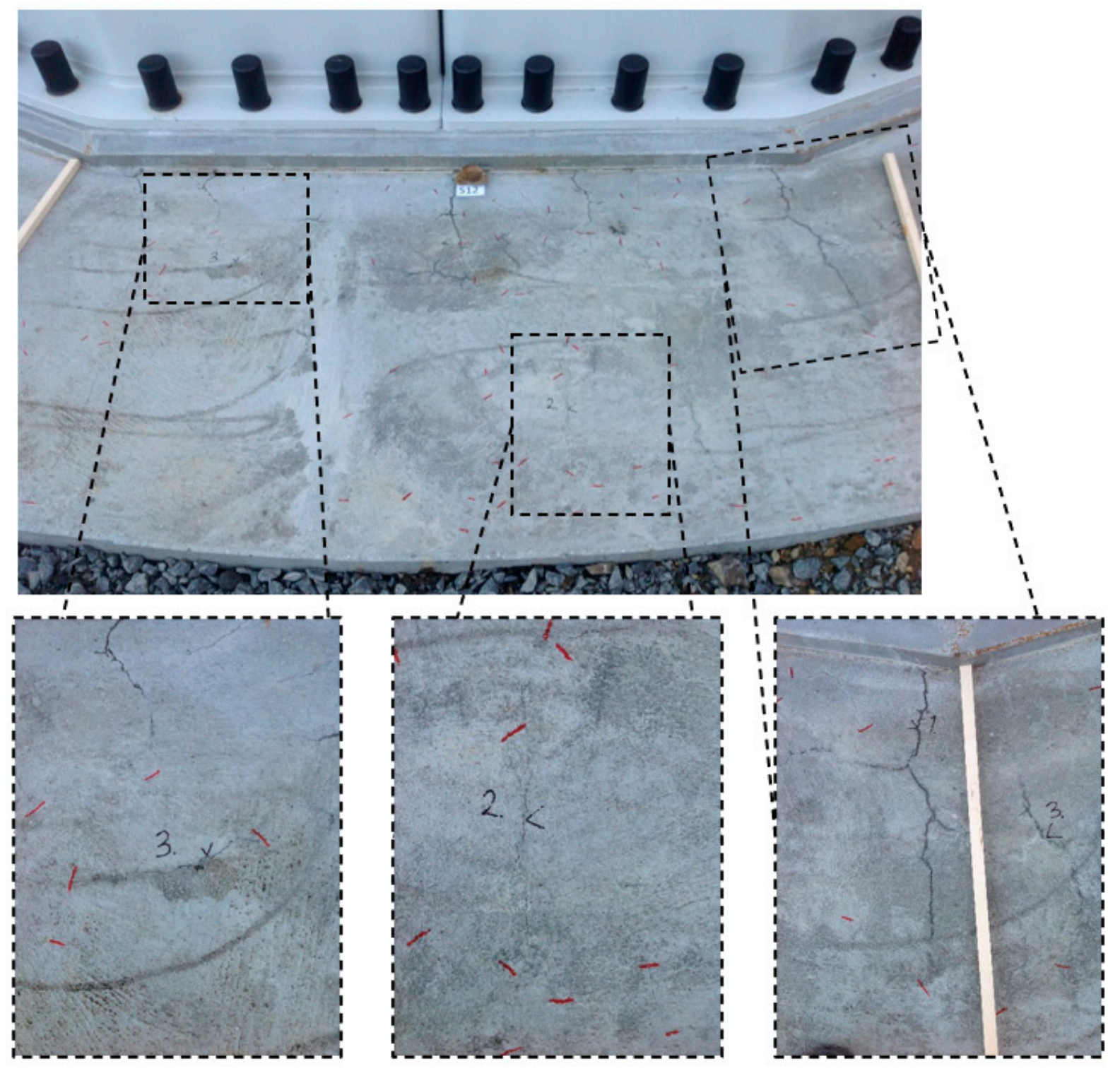

Figure 6. Cracks on the horizontal pedestal surface, including three zooms of selected areas, with red marks indicating the ends of the cracks and labels 1, 2, and 3 indicating arbitrary labelling of cracks on site.

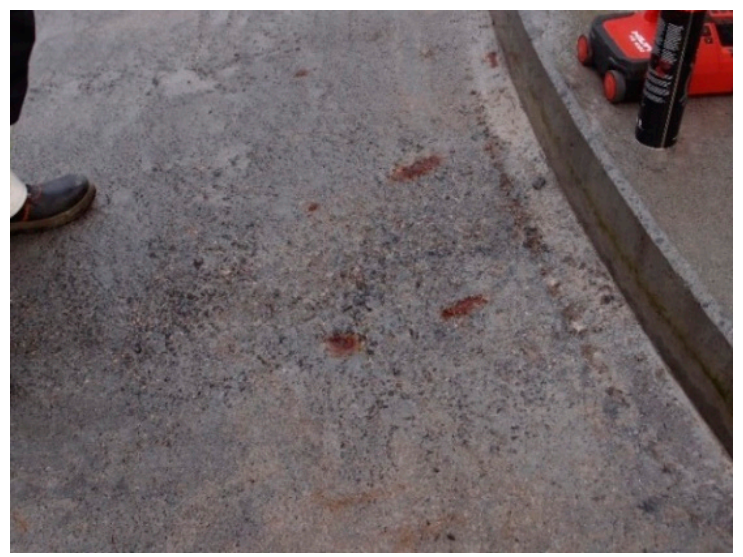

Figure 7. Rust marks observed on the inclined concrete surface of a foundation. 

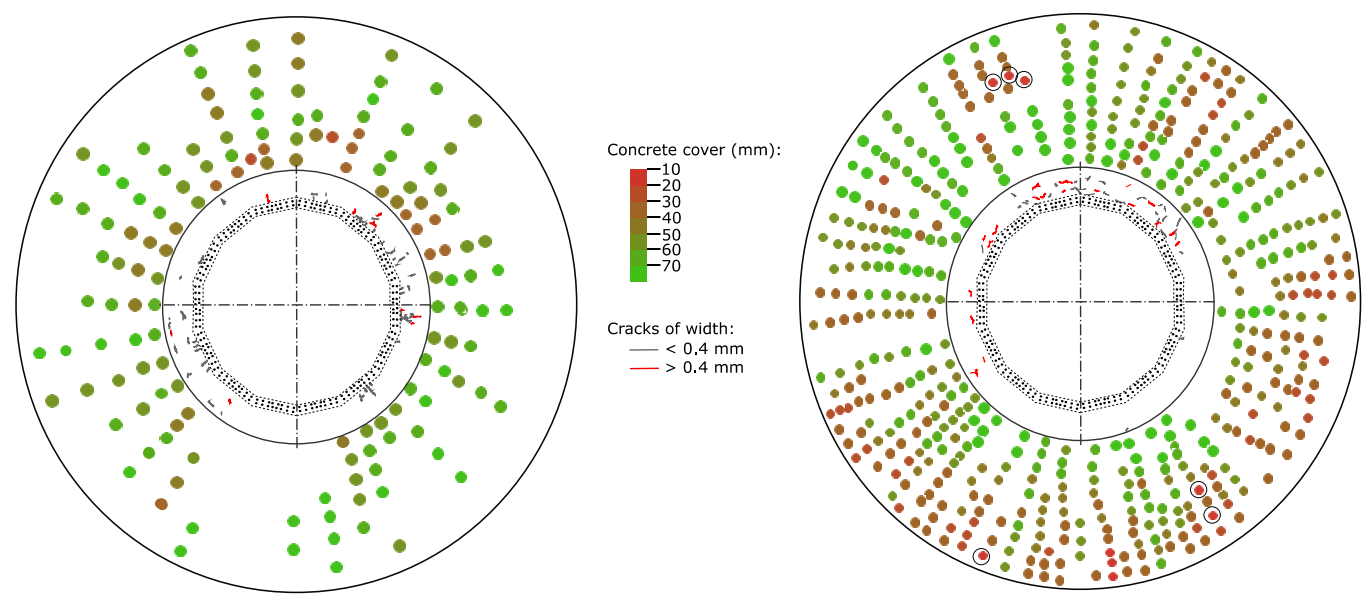

Figure 8. Concrete cover measures on the inclined surface and crack patterns on the horizontal pedestal surface.

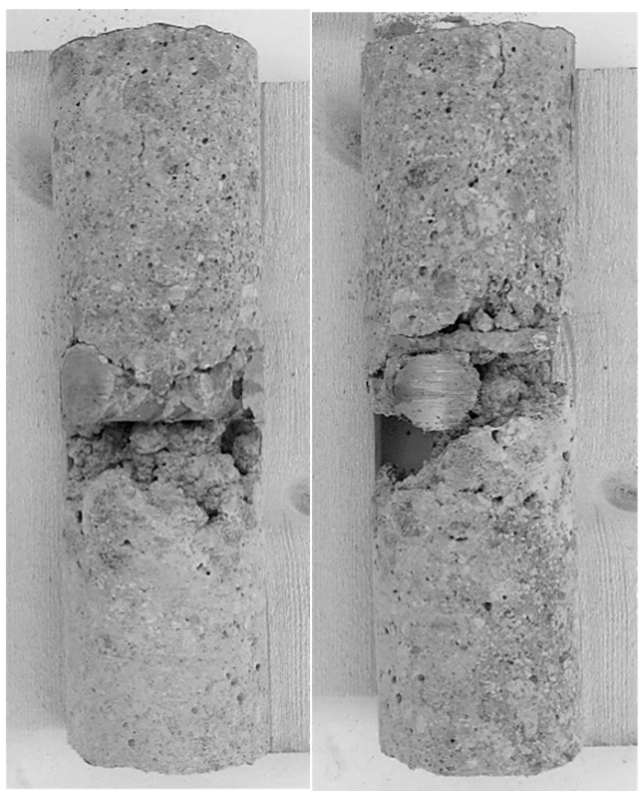

(a)

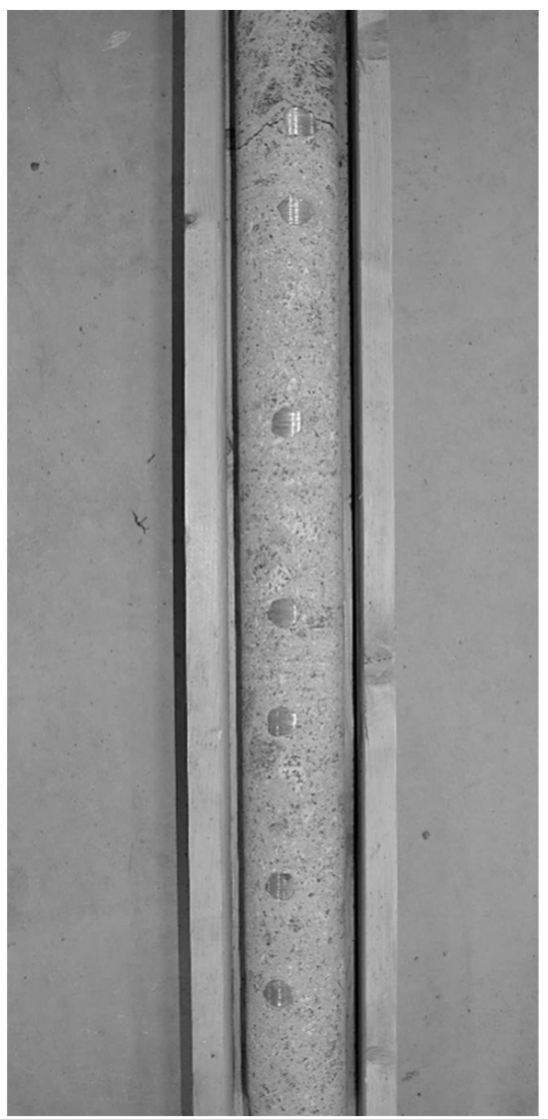

(b)

Figure 9. Cores vertically drilled from the foundations: (a) core drilled on the inclined surface at a plastic settlement crack, and (b) core drilled on the pedestal.

\subsection{Assessment of the Extent of the Defects and Relation to Production Aspects}

Two different teams of concrete workers each with their own supervisors, from two different subcontractors, were in charge of the on-site construction work for the gravitybased foundations. The two different teams are hereafter referred to as Team A and Team B. Table 3 summarizes the average time required to build a foundation and the average defect indexes for the foundations built by each team. The average time required for the casting of concrete for a gravity-based foundation was $15.6 \mathrm{~h}$. Team B worked significantly faster than team A, requiring on average $2 \mathrm{~h} 24$ min less. Team B also achieved the best overall 
quality for the foundations with a general defect index of 4.3 on average, i.e., $33 \%$ lower than Team A. This trend was observed both for the cracking defects (crack index $22 \%$ lower for Team B) and for the reinforcement and casting defects (index $61 \%$ lower for Team B).

Table 3. Production time per foundation and defect index for each production team.

\begin{tabular}{|c|c|c|c|c|c|}
\hline Production Team & $\begin{array}{c}\text { Number of } \\
\text { Foundations (-) }\end{array}$ & $\begin{array}{l}\text { Average Time per } \\
\text { Foundation for } \\
\text { Concrete Works (h) }\end{array}$ & $\begin{array}{c}\text { General } \\
\text { Defect Index (-) }\end{array}$ & Crack Index (-) & $\begin{array}{l}\text { Reinforcement } \\
\text { and Casting } \\
\text { Defect Index (-) }\end{array}$ \\
\hline All & 23 & 15.6 & 5.8 & 4.2 & 1.6 \\
\hline Team A & 13 & 16.6 & 6.7 & 4.6 & 2.1 \\
\hline Team B & 10 & 14.2 & 4.5 & 3.6 & 0.9 \\
\hline
\end{tabular}

Figure 10 shows the evolution of the casting time for the foundations built by Team A and Team B, respectively. As illustrated on this graph, the works were first conducted by Team $A$ and then by Team $B$. Three distinct construction groups can be identified: the first two for foundations built by Team A separated in time by an interruption of several months since no work was conducted during the colder winter months, and the third one for foundations built by Team B. Remarkably, the first foundation built in each of these three groups took significantly longer times than the following ones. There is a marked decreasing trend over time for the second group of foundations built by Team A and the third group built by Team B, while it is less clear for the foundations from the first group of Team A. When analysing the evolution of the general defect index over time, as shown in Figure 11, a clear decreasing trend can be observed for the third group built by Team B, while the trend is less clear for the two first groups built by Team A, where both the lowest and highest defect indexes are observed in the first foundations in each of these groups, followed by quite constant indexes for the subsequently built foundations.

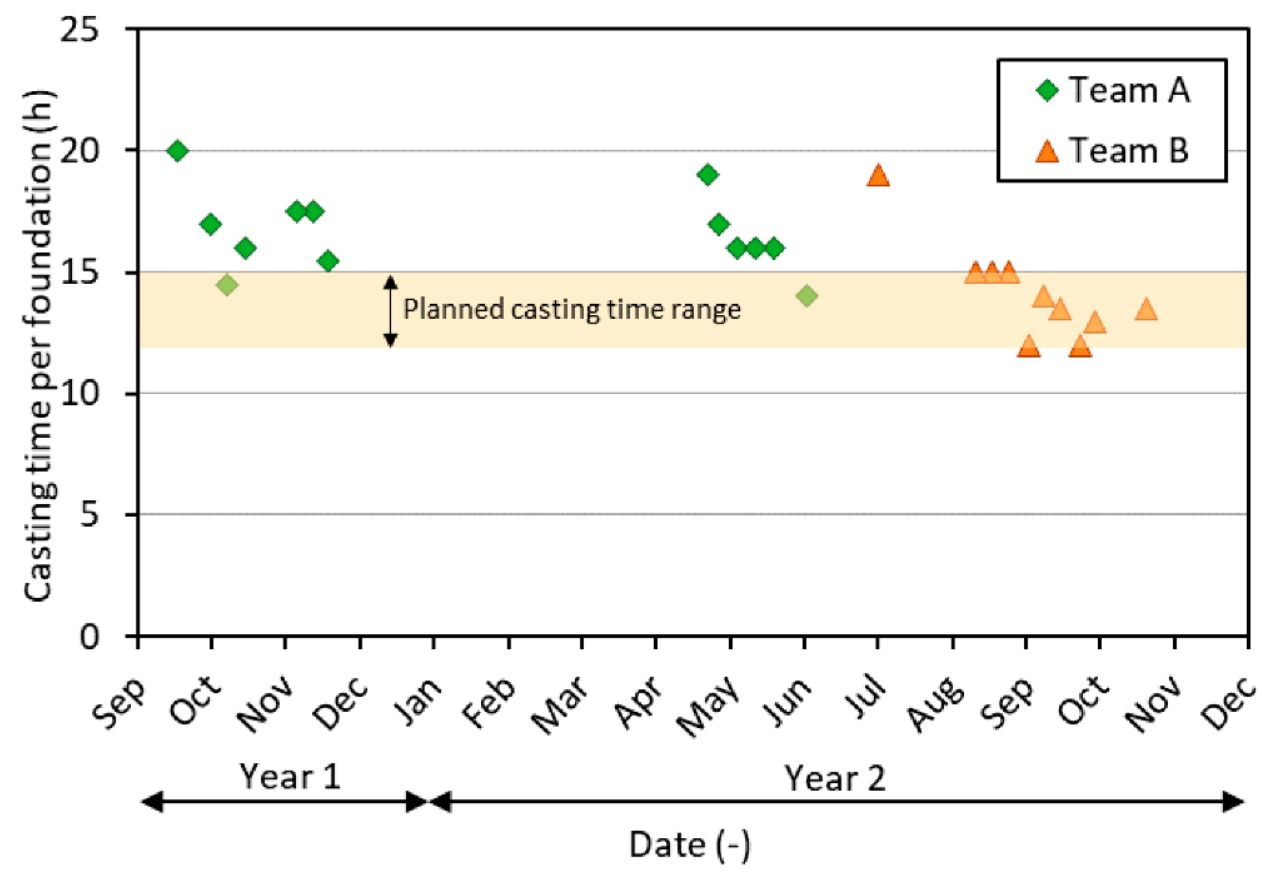

Figure 10. Relation between the time required for casting the foundation and their production date. 


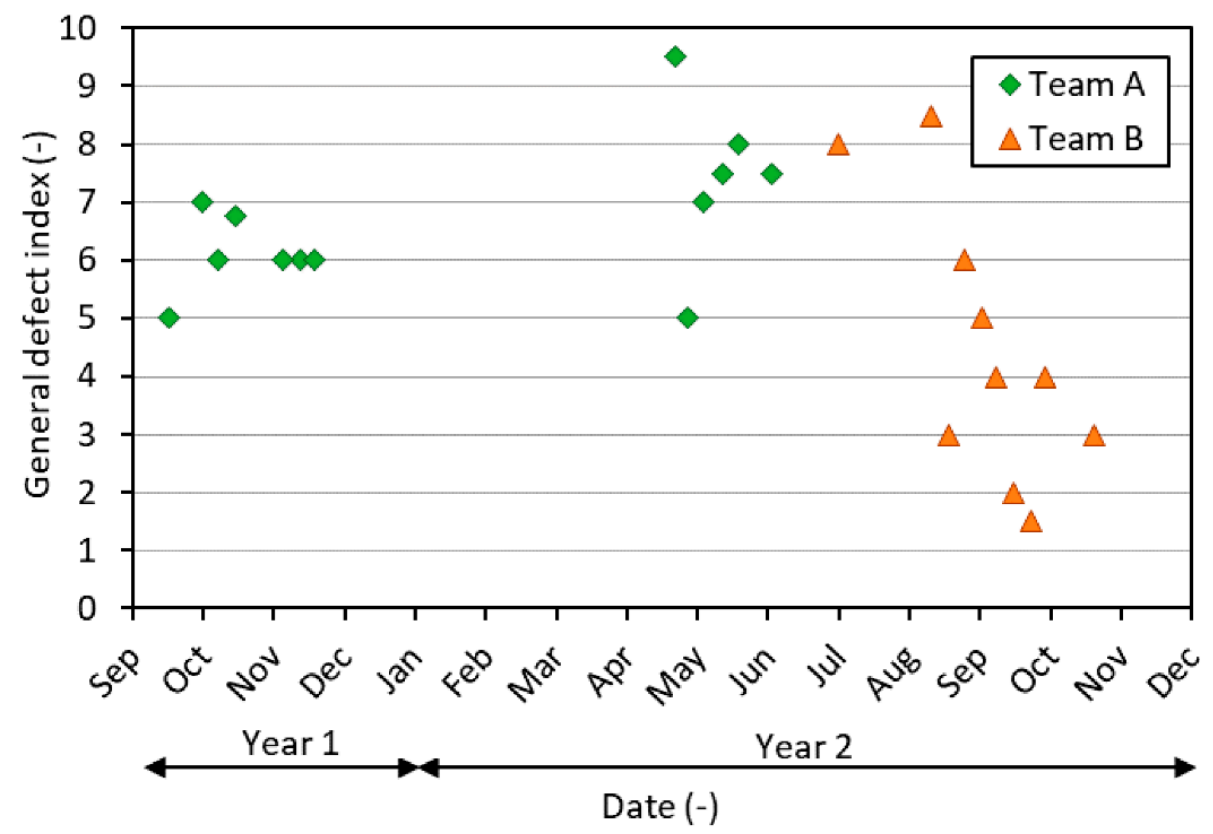

Figure 11. Relation between the defect index and the production date of the foundations.

The correlations between the weather conditions, and the casting time and extent of defects, respectively, were also investigated. As shown in Table 4, the average time per foundation was $15 \mathrm{~h} 36 \mathrm{~min}$ for all foundations, which was $12 \mathrm{~min}$ shorter on average for foundations cast under rainy or snowy conditions. The difference observed in terms of defects is more significant, as it is equal to 4.8 for foundations cast under rain or snow conditions and 6.1 for foundations cast under conditions without precipitations.

Table 4. Production time per foundation and defect index for different weather conditions.

\begin{tabular}{cccc}
\hline Weather Conditions & Number of Foundations (-) & Average Time per Foundation (h) & Average Defect Index (-) \\
\hline All weather conditions & 23 & 15.6 & 5.8 \\
\hline Without precipitations & 17 & 15.7 & 6.1 \\
\hline $\begin{array}{c}\text { With precipitations } \\
\text { (rain or snow) }\end{array}$ & 6 & 15.2 & 4.8 \\
\hline
\end{tabular}

A significant positive correlation is observed between the crack index and the time required to cast the foundations, as represented in Figure 12. The outlying point with a casting time of $20 \mathrm{~h}$ and a crack index equal to 1 corresponds to the first foundation constructed, as can be seen in Figure 10. Notes from the construction daily logs indicate that this foundation was cast under heavy rainfall.

The eventual correlations between the transport distance for the fresh concrete mix between the temporary concrete batching plant and the foundation, and the resulting casting time for the foundations and the evaluated cracking extent were also tested. As shown in Figure 13, the transport distance does not appear to have affected the casting time or to have had a clear influence on the outcome in terms of cracks (although the foundations that were transported more than $17 \mathrm{~km}$ showed a higher crack index on average than the foundations that were transported less than $10 \mathrm{~km}$, and their crack index was lower than that of certain closer foundations). 


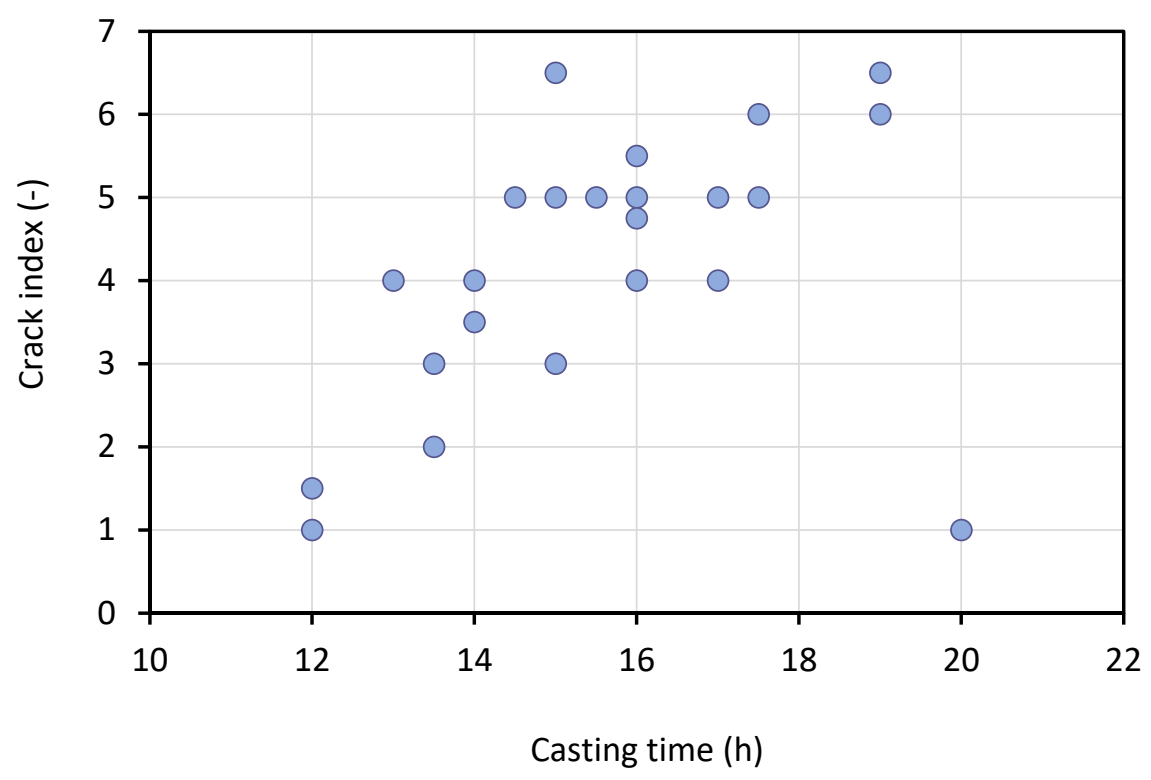

Figure 12. Relation between the crack index and time required for the casting of concrete.

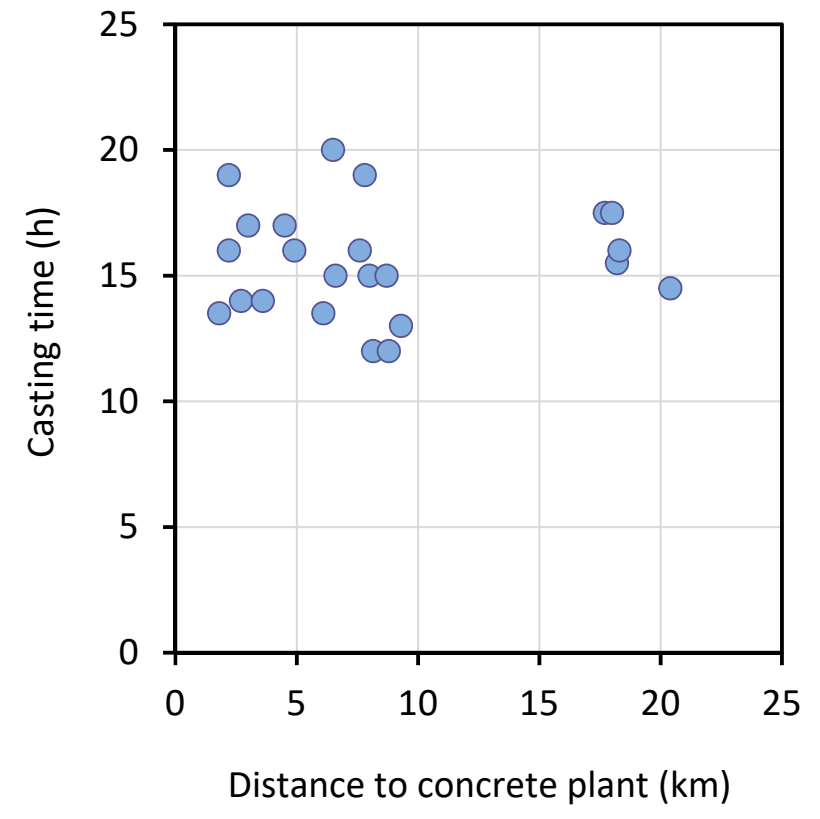

(a)

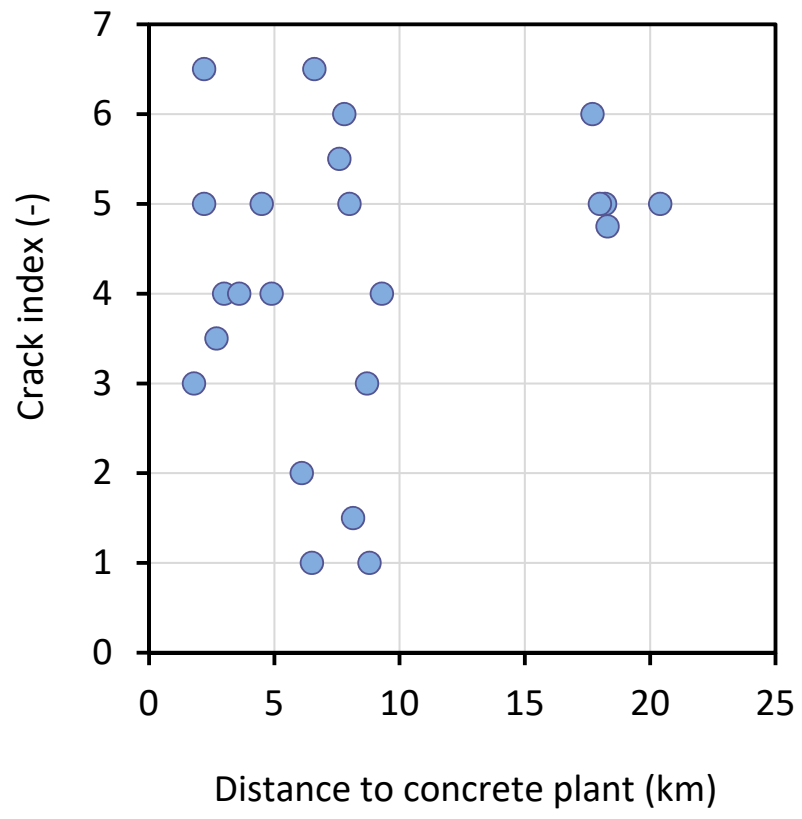

(b)

Figure 13. Casting time (a) and cracking index (b) with respect to the distance between the foundations and the temporary concrete batching plant on site.

\subsection{Results from Tests on Cores Drilled on the Foundations}

The results from carbonation tests on six cores drilled from four foundations after two to three years after casting (three at uncracked locations and three at cracks) revealed that the depth of carbonation was less than $1 \mathrm{~mm}$ in all cases except for one core taken out at a surface crack. In the latter, the carbonation appeared to follow the crack as it progressed to a depth along the crack of $15 \mathrm{~mm}$.

Figure 14 shows the results from tests on cores taken from the same four foundations to determine the density and in situ compressive strength at different ages. It is noteworthy that there is no clear connection between increased density and increased in-situ compressive strength. Cores taken in the depth interval 100-200 mm showed slightly lower in-situ 
compressive strength and density in average than those from the upper and lower intervals (0-100 $\mathrm{mm}$ and 200-300 $\mathrm{mm}$ ).

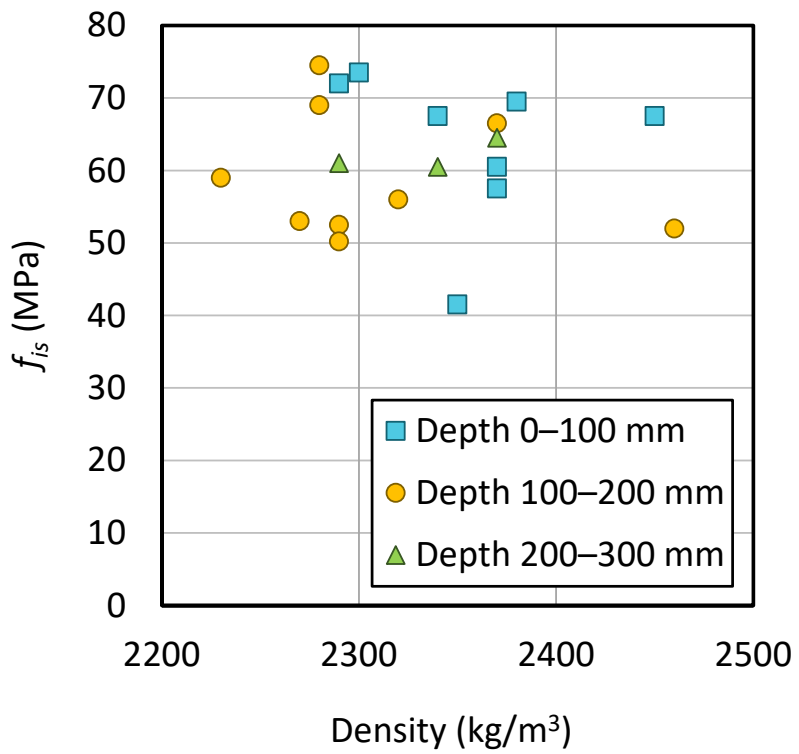

(a)

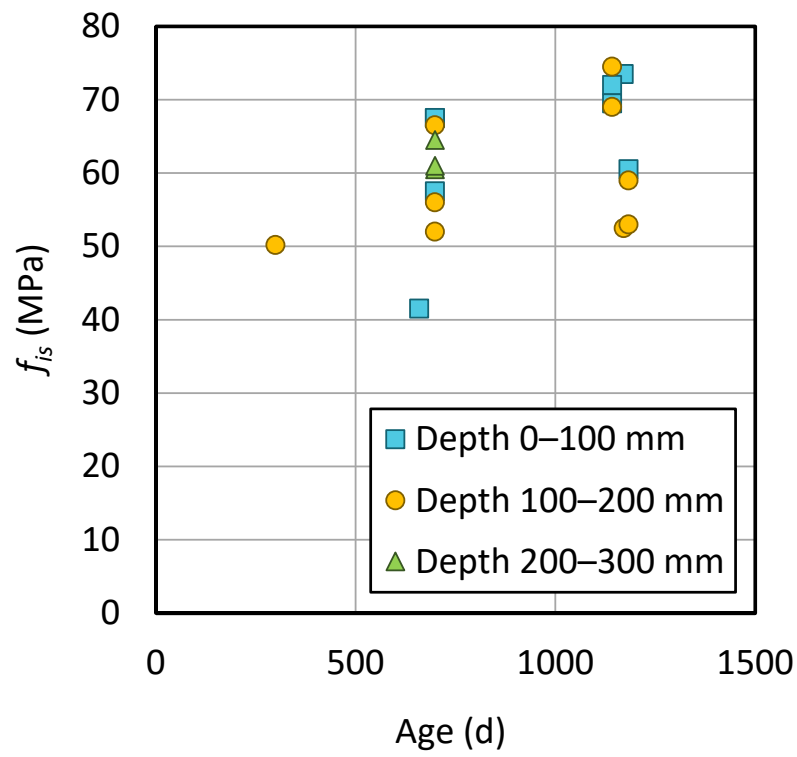

(b)

Figure 14. In-situ compressive strength, $f_{i s}$, versus (a) density, and (b) age of the concrete for test specimens taken from cores drilled on the foundations, for different depths from the top concrete surface.

Since the same concrete recipe and casting process were used for all foundations, the results reported in Figure 14 were treated as a whole to assess the in-situ compressive strength of the finished foundations based on the European Standard EN 13791 [25]. This assessment (the details of which are provided in Table 5) showed that the requirements for the concrete strength class $\mathrm{C} 35 / 45$ are met by a margin, both when considering all test results and when considering each depth range separately.

Table 5. Evaluation of the concrete strength class for the different depth ranges based on the mean and lowest in situ compressive strength $\left(f_{m(n), i s}\right.$ and $f_{\text {is,lowest }}$, respectively), and standard deviation $\sigma$, in accordance with EN 13791 [25].

\begin{tabular}{|c|c|c|c|c|c|c|}
\hline $\begin{array}{l}\text { Depth } \\
(\mathrm{mm})\end{array}$ & $\begin{array}{c}f_{m(n), i s} \\
(\mathrm{Mpa})\end{array}$ & $\begin{array}{c}f_{\text {is,lowest }} \\
\text { (Mpa) }\end{array}$ & $\begin{array}{c}\sigma \\
\text { (Mpa) }\end{array}$ & $\begin{array}{c}f_{c k, i s, \mathbf{1}}(\mathbf{1}, \mathbf{2}) \\
(\mathbf{M p a})\end{array}$ & $\begin{array}{c}f_{c k, i s, 2}(1) \\
(\mathbf{M p a})\end{array}$ & Concrete Strength Class \\
\hline $0-100$ & 63.7 & 41.5 & 10.5 & 48.2 & 45.5 & $\mathrm{C} 40 / 50$ \\
\hline $0-100(\bmod )^{(3)}$ & 66.9 & 57.5 & 5.9 & 58.2 & 61.5 & C55/67 \\
\hline $100-200$ & 60.3 & 52.0 & 8.6 & 47.6 & 56.0 & $\mathrm{C} 45 / 55$ \\
\hline $200-300$ & 62.0 & 60.5 & 2.2 & 55.0 & 64.5 & $\mathrm{C} 50 / 60$ \\
\hline 0-300 (all tests) & 62.0 & 41.5 & 8.6 & 49.3 & 45.5 & C35/45 \\
\hline
\end{tabular}

(1) $f_{c k, i s, 1}$ and $f_{c k, i s, 2}$ are obtained using Equations (1) and (2), respectively, in EN 13791 Section 7 [25]. (2) If $1.48 \sigma<7 \mathrm{MPa}, 7 \mathrm{MPa}$ is used according to EN 13791 [25]. ${ }^{(3)} 0-100$ (mod) corresponds to $0-100$ without the low outlying value obtained on one foundation.

\section{Discussion}

\subsection{Influence of Personnel, Weather, and Transport on the Observed Defects}

After their construction, a number of defects were observed on the foundations, which led to further inspections and investigations. These defects all appeared to be production related (i.e., not load-induced structural defects). 
A marked difference was observed in terms of the quality between the foundations produced by the two different teams in charge of casting concrete in the project. Several differences were observed between the two teams in terms of the organisational structure, communication, experience, and mentality. Team A was led by some of the skilled workers of the team, while Team B was led by a qualified supervisor and a site manager. While both teams did not understand Swedish, communication between the general contractor and Team A was in English (which was not the native language of either party) while a translator was used to communicate with Team B. Team A had extensive experience in casting wind turbine foundations while Team B lacked previous experience. According to the general contractor's personnel, this led to Team A having high confidence in their abilities to carry out the works as they used to do while Team B was keen to learn and receive directions. For instance, several meetings were organized between Team $B$ and the general contractor prior to the works, in which personnel from Team B described in detail how they were planning on conducting the works and received feedback. In this way, Team $B$ benefited from the experience in previous castings held by Team A. These findings match the results observed in previous research by Surahyo [20] that identified personnel (e.g., experience, knowledge, understanding of what is expected, and attitude) as the major factor causing variations in the quality of concrete in front of material, equipment, and workmanship in second position, and field testing in third position. Additionally, in the project studied, the attitude of the teams toward planning and learning appears to have been more important than their previous experience. It was also observed in the present study that the team that produced foundations with less defects also produced them in a shorter time.

This study did not find conclusive evidence of a correlation between the weather conditions recorded (i.e., precipitations and temperatures) and the time or quality of the foundations produced under these conditions. Nevertheless, the fact that the foundations cast under precipitations have a lower defect index in average, and that the outlying foundation in Figure 12 with a remarkably low defect index was cast under heavy rain, suggest that precipitations may have led to less observable defects. Rainwater may have helped the hydration and curing processes on the top concrete surface. When it comes to the surface cracks observed, the dense top layers of reinforcement may have impacted the settlement of the concrete in some places.

The transport distance of the fresh concrete did not appear to influence the casting time of the foundations. Although the transport distances varied considerably between the foundations, they remained in a range (under $21 \mathrm{~km}$ ) that is commonly not critical for the transport of concrete. Still, these results may be an indication that good concrete transport could be achieved during construction. Indeed, as the wind farm is located in a very remote location, as is often the case for wind farms, the distance to the nearest back-up concrete plant was large. Such an increase in the transport distance for the concrete would not only have implied a longer transport time, it would also have required a considerably larger number of concrete trucks to ensure the continuity of the delivery of concrete for the foundation casting, which may be difficult to obtain considering the limited availability of such trucks in these regions.

\subsection{Consequences and Measures to Ensure the Compliance of Wind Turbine Foundations}

The casting process used to build the foundations, and especially their top inclined surface, did not appear to have led to non-conformities in terms of the compressive strength, since the results from the tests on the cores indicate that the concrete fulfils the requirements for the strength class C35/45, as specified in the design. It should be noted that standards allow the field-measured in situ strength to be $15 \%$ lower than the one measured on standard test specimens during the casting process to achieve the same compressive strength class [25]. This deviation forms part of the partial safety factor for concrete used in design [23]. 
The likelihood of the occurrence of certain deviations during construction is considered in the design of concrete structures. The possibility of worsened bond conditions is taken into account in EN 1992-1-1 [23] by a reduction factor, $\eta_{1}$. This factor reduces the bond strength by $30 \%$ in cases where poor bond conditions may occur, e.g., in the case of bars placed in the top $300 \mathrm{~mm}$ during concreting of elements with a height of more than $600 \mathrm{~mm}$. For wind turbine foundations, this applies to the top layers of bars, which may be affected by plastic settlement cracks and not optimally enveloped by the concrete.

Carbonation developed quickly and locally in the cracks since the concrete around the cracks comes into contact with carbon dioxide more easily and rapidly. Differences can occur depending on the crack width but also the moisture condition in the crack. Carbonation has been observed on a single test to penetrate the concrete along a crack and reach a depth corresponding to the cover layer, which is not necessarily critical for corrosion [17]. It is important to ensure that the crack widths are limited according to the requirements of the standard.

The decision was made between the different actors of the construction project to seal cracks that were wider than $0.3 \mathrm{~mm}$. This crack width can be compared to the limiting calculated crack width according to the design standards. However, it should be noted that the design crack limitations are intended for load-induced cracks while in the studied project, the observed cracks are production related. The applied environmental exposure class $(\mathrm{XC} 4 / \mathrm{XF} 3)$ led to the requirement of a maximum water-to-cement ratio of 0.55 [26]. As the design service life of the foundations is 25 years, the limiting design crack width was chosen to be equal to $0.4 \mathrm{~mm}$, which corresponds to the requirement for a design service life of 50 years, according to the Swedish provisions on the application of the European construction standards [27]. Indeed, the shorter design service life covered by the standards is 20 years, for which no design crack width requirements are specified. The purpose of these design requirements is to determine the reinforcement required to withstand the theoretical design load effects while limiting crack widths in the concrete. Furthermore, the design crack width limitations are specified at the reinforcement level while the observed ones are measured at the concrete surface. Besides, concrete has self-healing properties to some extent in the presence of water for cracks that are under a certain width of less than $0.2-0.3 \mathrm{~mm}[28]$.

Although the minimum concrete cover was specified on the drawings as $50 \mathrm{~mm}$ by the designer, a lower concrete cover would have been sufficient to satisfy the requirements of the design standards. Indeed, the specified value was obtained by rounding up the nominal concrete cover according to the design standards (i.e., $42 \mathrm{~mm}$ ), which also include an allowance of $10 \mathrm{~mm}$ for deviations. It is the minimum concrete cover requirement regarding the bond of the reinforcement that governed this value (equal to the maximum bar diameter of $32 \mathrm{~mm}$ ), with the requirement regarding durability being lower (equal to $30 \mathrm{~mm}$ for the exposure class $\mathrm{XC4}$ / XF3 and design life of 50 years, also including the $10 \mathrm{~mm}$ allowance for deviations). Additionally, since the reported water-to-cement ratios during the casting for the foundations with observed cracks were below 0.5 (between 0.45 and 0.46 ), the minimum concrete cover required to provide durability for a design service life of 50 years is reduced from 20 to $15 \mathrm{~mm}$ [27].

Although the design service life of wind turbines is commonly of 20 to 30 years, the structural design of the foundations is usually investigated taking into account longer durations than the service life of the wind turbines. For instance, characteristic loads are often calculated for a return wind speed of 50 years. Besides, when it comes to durability requirements, crack width limitations and concrete covers are usually chosen for a design service life of 50 years.

The effects and consequences of a poor casting process may lead to repair work. In the case of wind turbines, the time for remedying eventual defects from the production to conducting the inspection is very limited before the foundations are entirely covered by earth. In the present project, the foundations were already covered between one and seven days after the casting was completed to proceed with subsequent works and the 
installation of the turbines. Later inspection requires new excavations. In the studied project, additional structural calculations had to be carried out to ensure the stability of the turbines under such excavations, and sometimes, when the wind blew above a certain limit, it was necessary to cover the foundations again at short notice. In such cases, the extra cost due to non-conformities becomes substantial. When defects are discovered quite late or the decision on the measures to be undertaken takes time, it may require the contractor to come back and re-establish a working site. For the wind farm owner, a faulty casting process may lead to unplanned maintenance and down time of the power plant with an increase in operational costs and a lower revenue for the investors. However, in this study, a more detailed assessment of the observed defects indicated that most of these defects were not going to affect the function of the foundations during their design service life. This is partly due to the fact that the requirements in design standards include tolerances for certain deviations in the final construction object (e.g., the tolerance for deviations in the concrete cover or quality of bonding for reinforcement bars).

The surfaces that were judged to be defective were sealed. Besides, the casting of an additional layer of concrete was conducted when the concrete cover was inferior to $30 \mathrm{~mm}$ (in some cases due to incorrectly mounted reinforcement) after exposing the top reinforcement layers by high-pressure water jet removal of the top concrete layer.

The consequences of the observed defects may become more relevant and further assessment and monitoring may be required in the hypothetical case that lifetime extension of the foundations is considered, in line with a lifetime extension or upgrade of the turbines. Additional measures may be required to enable this lifetime extension. For instance in Denmark, among other requirements, an annual visual inspection of the foundations is required to detect cracks in concrete [29].

\subsection{Recommendations for Quality Control}

One observation from the work carried out for this study is that construction logs are often fragmentary, i.e., some information or even documents may be missing. This is a common issue in construction projects, which are usually one-off projects, where much of the information is recorded manually by different persons using a paper-based process in the midst of on-going construction works [30]. The documents are only later saved in digital format, and most of them are scanned, i.e., not saved in a fully searchable format. Furthermore, these issues with the documentation are presumably even more prevalent in wind farm projects, where the works are often carried out in challenging conditions and spread across different locations over a large area and at several kilometres from the construction site offices. Inspection documents are also mostly unsystematic, most likely due to a lack of a sufficiently clear definition of the information that needs to be collected (which may result from a preliminary lack of knowledge). Besides, records in the construction and inspection logs and reports exclusively include defects or deviations; they do not include positive observations of particularly well-achieved or successful parts of the works, which could also be of importance in terms of experience feedback and learning for subsequent works. There appears to be abundant room for further progress in terms of quality control and follow-up.

Quality control and monitoring is especially important when larger foundations are being built as the size of turbines is increasing, and less prevalent concrete mixes are being used to reduce greenhouse gas emissions associated with the construction of foundations. Less experience is available regarding these concrete mixes, characterized by the use of recycled concrete aggregates or partial substitution of cement by alternative cementitious materials such as fly ash or blast furnace slag [31], and on specific production aspects and eventual challenges associated with their use. 


\section{Conclusions}

The construction of wind turbine foundations poses numerous challenges that have often lead to cracking and other types of defects as mentioned in the literature, usually with little detail. The production-related defects observed on foundations at the wind farm used as a case study in this work constitute further evidence of these issues. This study was conducted to thoroughly document and analyse the defects encountered in the project and their relation to production aspects and design requirements.

The results of the assessment performed in this work highlighted that the personnel involved in the works had a clear influence on the quality achieved and the production time. The analysis indicates that the willingness of the concrete work teams to improve through discussion and feedbacks with the project management staff can overcome their limited experience of the type of work being undertaken.

Detailed assessments of the defects showed that many of the observed defects did not jeopardize the fulfilment of the design requirements, often thanks to allowances in design standards for deviations in the final construction object. Hence, the observation of defects or deviations does not necessarily mean that the design requirements are not satisfied. For other punctual defects and local deviations, repair works needed to be carried out (i.e., sealing of cracks and local castings to increase the concrete cover) to ensure compliance with the design requirements and confidence in the durability of the foundations during their service life.

The work conducted in this study provides evidence that to achieve reliable quality control, and facilitate eventual arbitration processes, there is a definite need to collect and report data from construction and inspection in a systematic and comprehensible way, and to store this data in an easily accessible and well-structured digital format. This will also allow experience to be turned into knowledge to be used in subsequent projects by analysing the collected data as was carried out in this study.

Author Contributions: Conceptualization, A.M. and J.M.; Methodology, A.M. and J.M.; Validation, A.M. and J.M.; Formal Analysis, A.M. and J.M.; Investigation, A.M. and J.M.; Resources, A.M. and J.M.; Data Curation, A.M. and J.M.; Writing-Original Draft Preparation, A.M.; Writing-Review \& Editing, A.M. and J.M.; Visualization, A.M.; Supervision, A.M.; Project Administration, A.M. and J.M. All authors have read and agreed to the published version of the manuscript.

Funding: This study was financially supported by the Swedish Wind Power Technology Centre (SWPTC) at Chalmers university of Technology and the Swedish construction company NCC under the project "Methods and material for sustainable and cost effective structural supporting systems for wind power plants". The purpose of the Centre is to support Swedish industry with knowledge of design techniques, as well as maintenance, in the field of wind power. The Centre is funded by the Swedish Energy Agency, as well as academic and industrial partners.

Acknowledgments: The authors would like to thank the construction project management staff for their collaboration and valuable inputs.

Conflicts of Interest: The authors declare no conflict of interest.

\section{References}

1. Global Wind Energy Council. Global Wind Report 2021; Global Wind Energy Council: Brussels, Belgium, 2021.

2. Hassanzadeh, M. Cracks in Onshore Wind Power Foundations-Causes and Consequences; Elforsk AB: Stockholm, Sweden, 2012.

3. Currie, M.; Saafi, M.; Tachtatzis, C.; Quail, F. Structural integrity monitoring of onshore wind turbine concrete foundations. Renew. Energy 2015, 83, 1131-1138. [CrossRef]

4. Bellmer, H. Schäden an Tragstrukturen für Windenergieanlagen; Fraunhofer IRB Verlag: Stuttgart, Germany, 2016; ISBN 9783816796039.

5. Eisenkrein, H.; Eck, T. VGB-Standard “Leitfaden für das Lebensdauermanagement für Gründung, Fundament und Turm von Onshore-Windenergieanlagen". In Proceedings of the 4. Kolloquium Erhaltung von Bauwerken, Ostfildern, Germany, 27-28 January 2015.

6. $\quad$ Rentzing, S. Dem Riss auf der Spur. Neue Energ. 2013, 8, 52-54.

7. Liu, W.; Tang, B.; Jiang, Y. Status and problems of wind turbine structural health monitoring techniques in China. Renew. Energy 2010, 35, 1414-1418. [CrossRef] 
8. Fowler, S. Cracks in Foundation Led to Wind Turbine's Collapse, 49 Others Also at Risk. Available online: https:/ /www.cbc.ca/ news/canada/new-brunswick/cracks-in-foundation-led-to-wind-turbine-collapse-1.6312668 (accessed on 17 December 2021).

9. TransAlta Kent Hills. Available online: https://transalta.com/plants-operation/kent-hills/ (accessed on 18 December 2021).

10. Armesto Barros, J.; Mathern, A. Recent and future trends of onshore wind turbine foundations. In Proceedings of the IABSE Symposium Prague 2022-Challenges for Existing and Oncoming Structures, International Association for Bridge and Structural Engineering, Prague, Czech Republic, 25-27 May 2022.

11. Wymore, M.L.; Van Dam, J.E.; Ceylan, H.; Qiao, D. A survey of health monitoring systems for wind turbines. Renew. Sustain. Energy Rev. 2015, 52, 976-990. [CrossRef]

12. McAlorum, J.; Perry, M.; Fusiek, G.; Niewczas, P.; McKeeman, I.; Rubert, T. Deterioration of cracks in onshore wind turbine foundations. Eng. Struct. 2018, 167, 121-131. [CrossRef]

13. Rubert, T.; Perry, M.; Fusiek, G.; McAlorum, J.; Niewczas, P.; Brotherston, A.; McCallum, D.; Rubert, T.; Perry, M.; Fusiek, G.; et al Field Demonstration of Real-Time Wind Turbine Foundation Strain Monitoring. Sensors 2017, 18, 97. [CrossRef] [PubMed]

14. The Concrete Society. Technical Report No. 22-Non-Structural Cracks in Concrete; The Concrete Society: Camberley, UK, 2010.

15. Transportation Research Board. Transportation Research Circular E-C107: Control of Cracking in Concrete: State of the Art: Control of Cracking in Concrete Structures-State of the Art; National Research Council: Washington, DC, USA, 2006.

16. Cement Concrete \& Aggregate Australia. What Are Plastic Settlement Cracks? Cement Concrete \& Aggregate Australia: St Leonards, NSW, Australia, 2005.

17. BRE Centre for Concrete Construction. DIG 444 Part 1 Corrosion of Steel in Concrete-Durability of Reinforced Concrete Structures; IHS BRE Press: Bracknell, UK, 2000; ISBN 1860813607.

18. Glasser, F.P.; Marchand, J.; Samson, E. Durability of concrete-Degradation phenomena involving detrimental chemical reactions. Cem. Concr. Res. 2008, 38, 226-246. [CrossRef]

19. Mathern, A.; von der Haar, C.; Marx, S. Concrete Support Structures for Offshore Wind Turbines: Current Status, Challenges, and Future Trends. Energies 2021, 14, 1995. [CrossRef]

20. Surahyo, A. Concrete Construction-Practical Problems and Solutions; Springer Nature Switzerland AG: Cham, Switzerland, 2019; ISBN 978-3-030-10509-9.

21. International Federation for Structural Concrete. fib Model Code for Concrete Structures 2010; Wilhelm Ernst \& Sohn: Berlin, Germany, 2013; ISBN 978-3-433-60408-3.

22. International Federation for Structural Concrete. Structural Concrete-Textbook on Behaviour, Design and Performance-Volume 1; International Federation for Structural Concrete: Lausanne, Switzerland, 1999; ISBN 978-2-88394-041-3.

23. European Committee for Standardization. EN 1992-1-1; Eurocode 2: Design of Concrete Structures-Part 1-1: General Rules and Rules for Buildings. European Committee for Standardization: Brussels, Belgium, 2004.

24. Alexander, M.; Bentur, A.; Mindess, S. Durability of Concrete-Design and Construction; Taylor \& Francis, CRC Press: Boca Raton, FL, USA, 2017; ISBN 978-1-4822-3725-2.

25. European Committee for Standardization. EN 13791:2007; Assessment of In-Situ Compressive Strength in Structures and Precast Concrete Components. European Committee for Standardization: Brussels, Belgium, 2007.

26. Swedish Standards Institute. SS 137003:2008; Betong-Användning av EN 206-1 i Sverige [Concrete-Application of EN 206-1 in Sweden]. Swedish Standards Institute: Stockholm, Sweden, 2012.

27. Boverket. EKS 8-Boverkets Föreskrifter och Allmänna Råd om Tillämpning av Europeiska Konstruktionsstandarder (Eurokoder) [Boverket's Regulations and General Advice on the Application of European Design Standards (Eurocodes)]; Boverket: Karlskrona, Sweden, 2011.

28. Van Tittelboom, K.; De Belie, N. Self-Healing in Cementitious Materials-A Review. Materials 2013, 6, 2182-2217. [CrossRef] [PubMed]

29. Danish Energy Agency. BEK nr 1773 af 30/11/2020 Bekendtgørelse om Teknisk Certificering og Servicering af Vindmøller m.v. [Executive Order No. 1773 of 30 November 2020 on Technical Certification and Servicing of Wind Turbines]; Danish Energy Agency: Copenhagen, Denmark, 2020.

30. $\mathrm{Wu}, \mathrm{L}$.; Lu, W.; Xue, F. Construction inspection information management with consortium blockchain. In Proceedings of the 25th International Symposium on Advancement of Construction Management and Real Estate; Springer Singapore: Singapore, 2020; ISBN 978-981-16-3587-8.

31. Berndt, M.L. Influence of concrete mix design on $\mathrm{CO}_{2}$ emissions for large wind turbine foundations. Renew. Energy 2015, 83, 608-614. [CrossRef] 